\title{
Development of regulatory universal learning actions of adolescents by means of additional education
}

\author{
Gennadii Mikhailovich Golubchikov ${ }^{1, *}$ Marina Gennadievna Golubchikova ${ }^{2,3}$, and Svetlana \\ Albertovna Kharchenko ${ }^{2}$ \\ ${ }^{1}$ The East Siberian branch of the Federal State Budget-Funded Educational Institution of Higher \\ Education " The Russian State University of Justice" (the city of Irkutsk), Irkutsk, Russia \\ ${ }^{2}$ Irkutsk State University \\ ${ }^{3}$ Irkutsk State Medical Academy of Postgraduate Education - Branch Campus of the Federal State \\ Budgetary Educational Institution of Further Professional Education "Russian Medical Academy of \\ Continuing Professional Education" of the Ministry of Healthcare of the Russia Federation, Irkutsk, \\ Russia
}

\begin{abstract}
The system of supplementary education at the present stage of development serves as a pedagogical structure, maximally adapting to the needs of students, providing each of them with the greatest freedom of choice in terms of psychological comfort, as well as the possibility of creative development at an individual pace. Programs of supplementary education of sports orientation, the most popular among adolescents, with a competent pedagogical approach to the organization of the activities of the teacher and students are the most effective environment for the education and development of personal and meta-disciplinary skills. In our study, we present a variant of the solution of the indicated problems on the example of one of the directions of martial arts, revealing the possibilities of the whole educational system, which is traditional karate, in the upbringing and development of schoolchildren, not a single sport.
\end{abstract}

\section{Introduction}

The pace of change in the modern world increases every year. A person of our time, to be successful, must have personal qualities that will allow him/her not only to keep up with current events but also to contribute to the further development of the surrounding reality. One of these characteristics, combining a variety of knowledge, skills, personal qualities, in our view, is independence. Traditionally in pedagogical science and practice, both past and modern education, the problem of learning autonomy is considered in relation to students and the school educational process [1].

Considering the system of Federal State Education Standards in school education, we rely on the educational results presented in them, which are combined into three groups: personal, meta-disciplinary, and subject, and we also refer to the concept of "universal learning activities (ULA)," introduced into the categorical apparatus of pedagogy in connection with

\footnotetext{
*Corresponding author: atletsport@mail.ru
} 
the appearance of the FSES. In a broad sense, the term "universal learning activities" means the ability to learn, that is, a person's ability to self-development. In a narrower sense, this term can be defined as a set of ways of action of the student, providing independent learning of new knowledge, the development of skills, including the organization of this process [2].

In our opinion, among all the ULAs, which include personal, regulative, cognitive, and communicative, it is the regulative ones that form the basis for the development of all the others and thus create the basis for the development of personality autonomy. According to many researchers of this problem, "Regulatory ULAs are cross-cutting in nature, 'permeating' communicative, personal, and cognitive ULAs. They are a kind of "backbone" in the structure of ULA because self-regulation is a - vertical, penetrating all levels of the personal system" [3].

Therefore, it is difficult to overestimate the importance of the regulatory ULA in the development of an independent and self-developing modern individual. As noted by the authors of the concept of developing universal learning activities (A. G. Asmolov, G. V. Burmenskaya, I. A. Volodarskaya, O. A. Karabanova, N.G. Salmina, S. V. Molchanov), regulatory universal learning activities (RULA) ensure the organization of the student's learning activities [4].

All this is particularly true for adolescence because subjective properties (activity, reflexivity, independence, responsibility, autonomy, etc.) are developed most intensively just in adolescence (D.I. Feldstein, G. A. Zuckermann, D.A. Leontev, M.A. Schukina, etc.) Adolescence is a sensitive age for the development of conscious learning activities. The learning activities of younger adolescents become self-regulated, the ability to achieve the goal and the need for self-change develops (D.I. Feldstein, I. V. Dubrovina, V. I. Morosanova, A. K. Osnitsky, etc.)

Given the importance and complexity of the tasks associated with the education of an independent personality, it is important to combine the efforts of all components of Russian education, understanding that only a general education school alone will not be able to do this sufficiently well. In this regard, the role of the system of supplementary education for children, as an important educational and developmental environment, aimed to a greater extent at achieving personal and meta-disciplinary results, is increasing.

\subsection{Extent of development of the problem.}

To date, there are papers revealing the peculiarities of the development of individual universal learning activities (N.P. Anisimova, V. V. Davydov, A. V. Zakharova, V. P. Zinchenko, E. V. Ilienkov, O.N. Molchanova, V. I. Morosanova, G. A. Zuckermann, etc.). A number of papers describe individual methods of developing the self-organization skills of younger pupils (A. B. Vorontsov, V. V. Donskov, L. V. Zharova, A. S. Lynda, E. V. Minaeva, E. V. Minzdaeva, L. P. Nikitina, I. E. Syusyukina, G. A. Zuckermann, etc.). Many papers reveal the psychological features of the development of universal learning activities (N.P. Ansimova, V. V. Davydov, A. V. Zakharova, V. P. Zinchenko, E. V. Ilienkov, A. K. Mrkova, O.N. Molchanova, etc.). Thus, the pedagogical means of stage-by-stage RULA development have not been studied sufficiently, the conditions that ensure the success of this process have not been identified, and the issue of diagnosing the level of RULA development remains problematic [5].

Undeveloped methodological support for the development of regulatory universal learning activities negatively affects the level of its organization and the results of education [6]. Studies by N.P. Ansimova, Z. A. Kokareva, M.V. Matyukhina, etc. show that teachers do not pay enough attention to this issue. Thus, despite the numerous studies in this direction, usually of applied nature, there are many undeveloped moments in the study of pedagogical 
methods and techniques of RULA development, especially in the system of supplementary education for children.

Over the past few decades, the popularity of traditional karate has become worldwide and has increased significantly in Russia. At the same time, the diversification of different types of karate today continues. So, only traditional karate in Russia engaged in more than 5000 people, including 1500 people - in the Irkutsk region. Unfortunately, not always the understanding of this type of martial arts corresponds to its real purpose. Karate is not just a fighting technique, not a sporting duel, not a simple show of smashing solid objects with your head, hand, or foot. The purpose of the ancient Okinawan martial art was, indeed, "the ability to inflict a decisive defeat on an opponent with a single blow of the fist or foot. But from time immemorial, the old masters gave more importance to the spiritual side of this art than to the bare execution of the techniques" [7].

In our study, the psychological theory of activity and the system-activity approach to the organization of the educational process in the classes of traditional karate acts as a methodological basis. We rely on the following main points.

Any educational result, which the learning process is aimed at mastering, is a specific type of activity [8]. Therefore, the pedagogical coach, before teaching students the types of professional sports activities, should disclose the structure and content of each of them and make the subject of purposeful mastery.

2. According to the psychological nature of the process of mastering. L. C. Vygotsky pointed to two consecutive psychological processes of interiorization and exteriorization [9]. The teacher's implementation of the process of interiorization involves the organization of each student's performance of the activity that needs to be mastered and the construction of an individual "orientation scheme" [10] describing the structure and content of this activity in a materialized form (on paper). Next, the teacher organizes the process of mastering the content of this scheme by the student at the level of his consciousness. This is how an intellectual, mental image of professional activity is shaped. Further, according to A.N. Leontev, it serves as an orientation in the external practical material activity of the karate fighter in the process of exteriorization [11].

3. Achievement of educational results, as well as high indicators of its quality, cannot arise on their own, they are naturally associated with the level of organization of the teacher's educational activity [12].

4. Design the structure and content of each type of activity, and the necessary subject knowledge is performed by the teacher on the basis of modeling procedures of the systemactivity method in "didactic orientation schemes" of two types: a reference map and a reference table [10]. The reference map is a model of professional activity, revealing its structural stages (motivational, orienting, planning, performing, self-control, selfassessment, self-correction, reflection) and content components in each of them (purpose, subject, technology, techniques, methods, means, forms, actions and operations, product, result).

5. Individual orientation schemes built as a result of educational research by the student himself/herself in the form of reference maps and reference tables act as a "tool" of the student's independent activity, developing his/her learning independence and the zone of "the nearest professional development" [10].

6. The developed pedagogical means can be used with the guidance of the pedagogical coach by parents who want to help their child in the organization of independent practice activity.

\section{Materials and methods}

Chapter II, "Experimental study of the development of regulatory universal learning activities of adolescents in supplementary education", describes the study of pedagogical conditions 
for the development of universal learning activities of adolescents in supplementary education on the example of traditional karate classes. Following the main provisions of this methodology, we have developed a methodology for teaching traditional karate to 10-15 year-olds, which allows them to simultaneously develop their regulatory skills. The following can be identified as distinguishing characteristics of this methodology.

1. Before teaching adolescents this or that kind of activity of a karate fighter, a pedagogical coach should build a model of an athlete's activity in protection and attack, revealing its structural stages and content components at each of them as an integral system unit and make it a subject of purposeful mastering by students, based on modeling procedures of the system-activity method.

2. The teacher should first design the activity model himself/herself in a materialized form (on paper) in the didactic tool "Reference map" we described above.

3. The models of different types of professional activity of a karate fighter should also include the subject knowledge necessary for its implementation, which the teacher can systematize by procedures of system synthesis method in a didactic tool "Reference table" (one or several).

4. The immediate activity of a karate fighter is a constantly changing game situation on the tatami. Regardless of the function performed, the fighter constantly performs two types of tasks: defensive tasks and offensive tasks. This involves mastery of combinations of attack and defense activities and the factors that condition the transition from one type of task to the other: defense-defense; defense-attack; attack-defense; attack-attack.

4. The teacher's method of organizing the process of teaching adolescents different types of karate activities should correspond to the psychological nature of the process of mastering, which consists of two successive psychological processes of interiorization and exteriorization. Their implementation implies the inclusion of each adolescent in the training and research activity at the first stage of the training session.

5. Speech forms are important for the implementation of the processes of interiorization and exteriorization in teaching activities. Speaking the activity out loud to the adolescent promotes more rapid formation of its mental image in his or her mind.

6. The mastering of karate activities by adolescents is determined by the level of organization of the pedagogical coach's teaching activity, aimed at organizing a system of conditions to ensure that each student achieves quality results. This requires the development of new didactic materials for the management of each adolescent's individual educational and occupational activity. Such means can be the Methodological manual for the pedagogical coach "Activity of a karate fighter in didactic orientation schemes", the Collection of individual orientation schemes for a karate trainee, "Diary of a fighter of a martial arts sports club.

To experimentally confirm the effectiveness of the designed set of pedagogical conditions of development in adolescents 10-15 years old of specific regulatory ULAs, a teaching experiment was arranged, which was conducted on the basis of the martial arts sports club of Irkutsk "Fudo-Jitsu". Thirty-six teenage boys and girls participated in it. Two groups were created - a control and an experimental, which consisted of students in the traditional karate classes in the amount of 18 people in each group. At the same time, the representatives of both groups did not differ in the main studied parameters at the ascertaining stage.

Since we realized the difficulty of including children in the work with new pedagogical means, the experimental group was created from volunteers who willingly performed the tasks of the coach and were systematically included in all types of training, competitive activities, went to the summer health camp for sports training camp. The pedagogical experiment was conducted from September 2016 to September 2018. Training sessions with groups were held three times a week. 
At the beginning of the experimental study, a primary study was conducted to determine the level of adolescents' mastery of specific regulatory ULAs to confirm the efficiency of the developed set of pedagogical conditions through training adolescents in specific types of karate activities; a formative experiment was organized for two years not only in classes but also during trips to competitions, in a holiday colony at sports camps.

\section{Results and discussion}

At the end of the experimental study, a follow-up cross-section was conducted to determine the level of adolescents' mastery of the regulatory ULAs, as well as their success in participating in competitions. Here, we present our findings in a comparison of the ascertaining and controlling stages of the experiment. Thus, Figure 1 presents comparative data on the "goal setting" indicator. As we can see, changes occurred in the number of children in the experimental group with high and low levels of development of these RULAs.

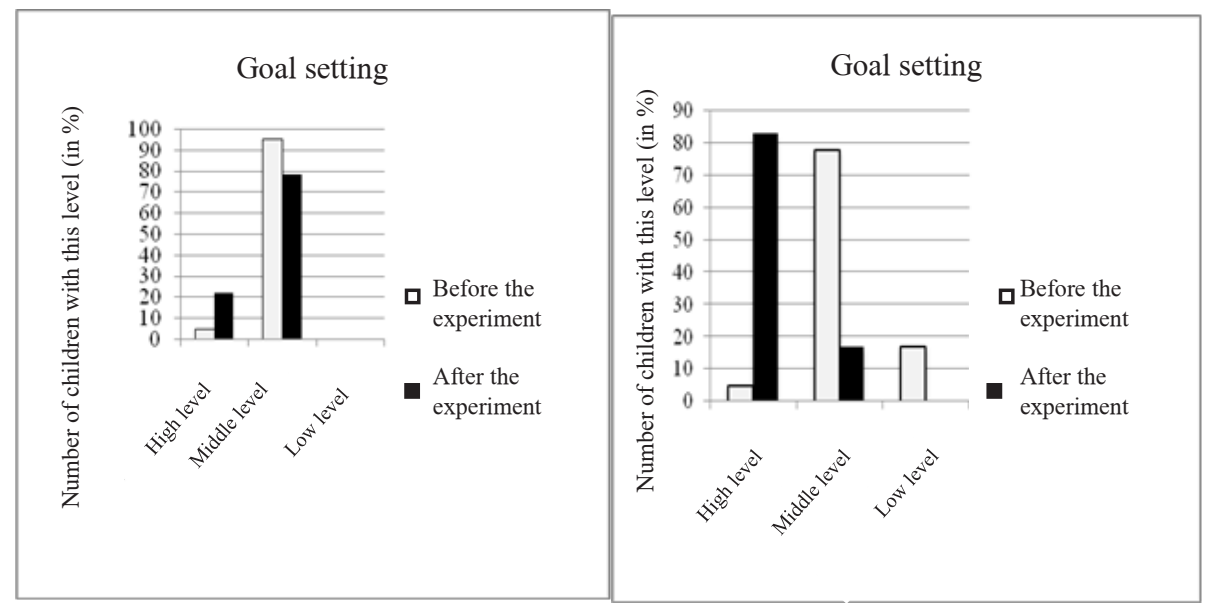

A) control group

B) experimental group

Fig. 1. Comparison of the distribution of adolescents by the level of RULA development (in \%) for the "goal setting" indicator

Figure 2 shows changes in the number of children in the control and experimental groups before and after the experiment by the "planning" indicator. Significant differences appeared in the children of the experimental group.

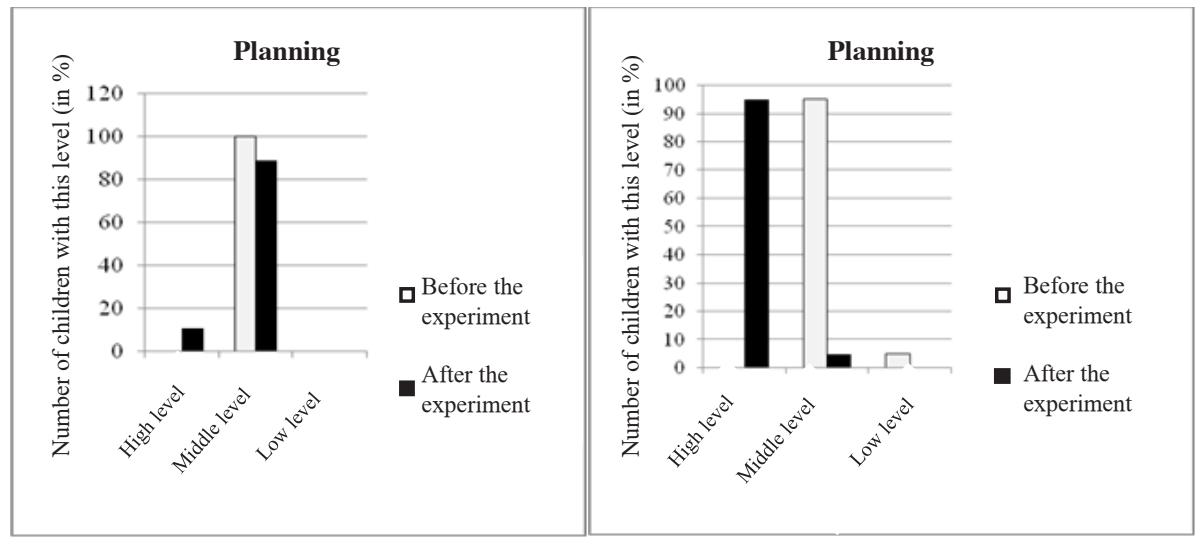

A) control group

B) experimental group 
Fig. 2. Comparison of the distribution of adolescents by level of RULA development (in \%) for the "planning" indicator

Where: Планирование - Planning; До эксперимента - Before the experiment; После эксперимента - After the experiment; Количество детей с данными уровнем (в \%) - Number of children with this level (in \%); Высокий уровень - High level; Средний уровень - Middle level; Начальный уровень - Low level;

Figure 3 shows changes in the "self-control" indicator, which correlate with the data of the "planning" indicator. Note that positive dynamics in the experimental group were also obtained by the "self-assessment" indicator.

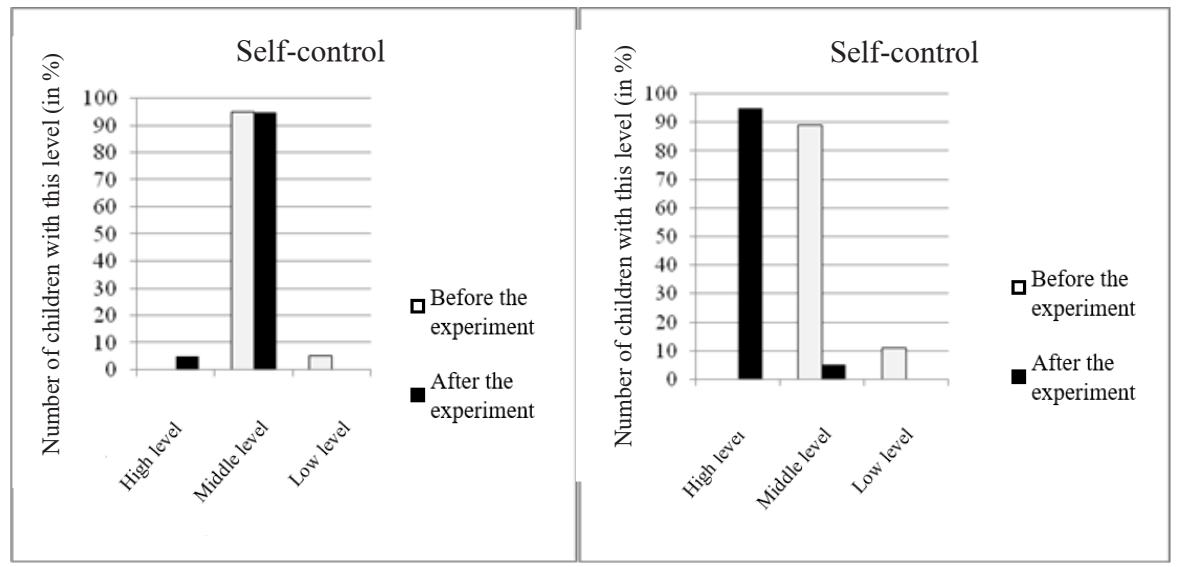

A) control group

B) experimental group

Fig. 3. Comparison of the distribution of adolescents by the level of RULA development (in \%) for the "self-control" indicator

Where: Самоконтроль - Self-control; До эксперимента - Before the experiment; После эксперимента - After the experiment; Количество детей с данными уровнем (в \%) - Number of children with this level (in \%); Высокий уровень - High level; Средний уровень - Middle level; Начальный уровень - Low level;

The "self-assessment" indicator is shown in Figure 4. The data indicate significant changes in the experimental group of adolescents.

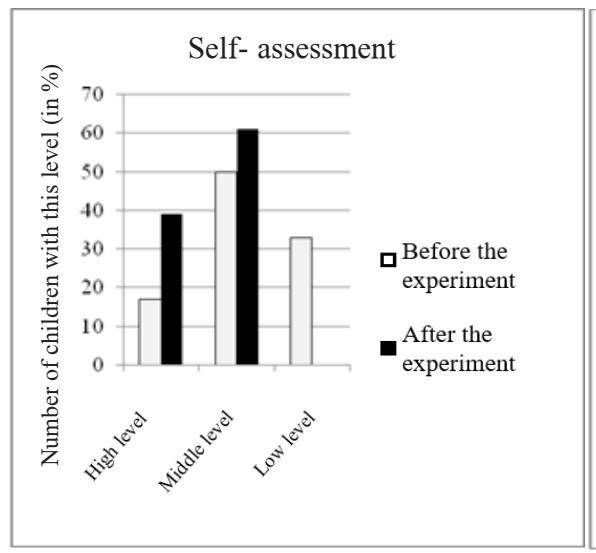

A) control group

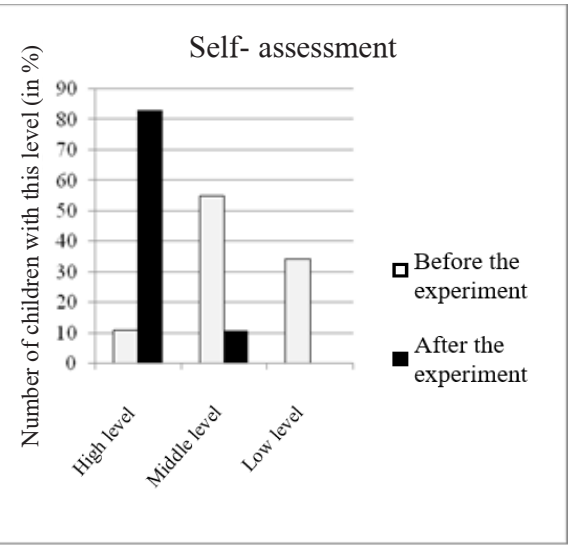

B) experimental group

Fig. 4. Comparison of the distribution of adolescents by the level of RULA development (in \%) for the "self-control" indicator 
In addition to the RULA indicators, we thought it important to track the dynamics of adolescents' achievements in sports activities, manifested in the number of victories in competitions at various levels. Increases in this indicator occurred in children of both groups, but significant differences were shown by adolescents in the experimental group.

Applying the Mann-Whitney test, we also confirm that reliable differences in the control group at the control stage of the experiment compared with the ascertaining stage occurred in the "self-assessment" indicator and data on "achievements" of participants. At the same time, this Mann-Whitney test shows significant valid differences between the control and the ascertaining stages of the experiment in the experimental group on all tested indicators: goal setting, planning, self-control, self-assessment, achievement. These criteria are significant at the $p<0.5$ level. Statistical processing of the data using the Spearman rank correlation coefficient also confirmed the significance of the results obtained. In the control group, a significant correlation at the $\mathrm{p}<0.5$ level was observed between the indicators "selfassessment" and "achievement" at the ascertaining stage; at the control stage, in the control group, some changes are observed, and a correlation is established between the same indicators as at the initial stage, only the parameter "planning" is added; in the experimental group at the ascending stage, no significant correlations were observed; at the control stage in the experimental group, significant dependences appeared in the indicators "planning", "self-control" and "self-assessment".

\section{Conclusions}

According to the results of the study, we can conclude that traditional karate classes are a favorable environment for the development of not only the specific skills of adolescents, their physical qualities but also allow them to solve the problems set in the Federal State Educational Standards of General Education, namely to develop regulatory universal learning activities related to the meta-disciplinary educational outcomes. Since sports activities take the leading place in the choice of areas of supplementary education by students and their parents, it seems necessary and possible to use different kinds of sports to form and develop all personal and meta-disciplinary universal learning activities. In our paper, we showed this on the example of traditional karate classes. The set of pedagogical conditions for the development of regulatory RULAs of adolescents that we have designed can also be used in other kinds of sports. We also understand the prospects of applying pedagogical tools to all participants in the educational process, both in our club and on the sites of work with adolescents on a mass scale.

\section{References}

1. M. Golubchikova, S. Kharchenko, E. Nikitina, Revista ESPACIOS, 38(49) (2017)

2. A. G. Asmolov, How to design universal learning activities in school, 169 (2011)

3. Developing students' regulatory universal learning activities, From the experience of the State budgetary general educational institution Lyceum No. 214 of the Central district of St. Petersburg, https://214spb.edusite.ru/

4. A.G. Asmolov, G.V. Burmenskaya, I. A. Volodarskaya, Developing universal learning activities in the basic school: from action to thought, The system of tasks, 159 (2010)

5. O.V. Kuznetsova, Developing the regulatory universal learning activities of junior students in the learning process (2015)

6. N.A. Dubovskaya, Problems of Modern Pedagogical Education, 55-5, 57 (2017)

7. A.A. Maslov, The Warrior's Way, Secrets of Martial Arts of Japan, 432 (2004) 
8. I. I. Ilyasov, Designing a course of study in an academic discipline: a manual for teachers, 208 (1994)

9. L. S. Vygotsky, Collected edition, 2, 287 (1982)

10. O. M. Kolomiets, Pedagogical Journal, 5, 47 (2016)

11. A.N. Leontev, Activities, Consciousness, Personality, 352 (2004)

12. N.N. Nechaev, Psychology: collected psychological papers, 184 (2014) 